\title{
Cardiothoracic
}

Transplantation

\section{Experimental lung preservation with Perfadex: Effect of the NO-donor nitroglycerin on postischemic outcome}

\author{
Thorsten Wittwer, MD, $\mathrm{PhD}^{\mathrm{a}}$ \\ Johannes M. Albes, MD, PhD \\ Antonia Fehrenbach, $\mathrm{PhD}^{\mathrm{b}}$ \\ Thomas Pech, MS ${ }^{\mathrm{a}}$ \\ Ulrich F. W. Franke, $M D^{a}$ \\ Joachim Richter, MD, $\mathrm{PhD}^{\mathrm{b}}$ \\ Thorsten Wahlers, MD, PhD
}

From the Department of Cardiothoracic and
Vascular Surgery, Friedrich-Schiller Uni-
versity, Jena, ${ }^{\text {a }}$ and the Department of Elec-
tron Microscopy, University of Göttingen,
Göttingen, Germany.
Supported by a grant from the Deutsche Forschungsgemeinschaft (DFG, Wa 738/3-4 and Ri 790/1-4).

Read at the Eighty-second Annual Meeting of The American Association for Thoracic Surgery, Washington, DC, May 5-8, 2002.

Received for publication May 30, 2002; revisions requested Aug 22, 2002; revisions received Oct 7, 2002; accepted for publication Oct 18, 2002.

Address for reprints: Thorsten Wittwer, MD, Department of Cardiothoracic and Vascular Surgery, Friedrich-Schiller University, Bachstrasse 18, 07740, Jena, Germany (E-mail: Th.Wittwer-MD@t-online.de).

J Thorac Cardiovasc Surg 2003;125: 1208-16

Copyright (C) 2003 by The American Association for Thoracic Surgery

0022-5223/2003\$30.00+0

doi:10.1016/S0022-5223(02)73244-3

\begin{abstract}
Objective: Optimal preservation of postischemic graft function is essential in lung transplantation. Antegrade flush perfusion with modified Euro-Collins solution represents the standard technique worldwide. However, growing evidence suggests the superiority of extracellular-type Perfadex solution (Vitrolife AB, Gothenburg, Germany) over Euro-Collins solution. During ischemia and reperfusion, endogenous pulmonary nitric oxide synthesis is decreased, and therefore therapeutic stimulation of the nitric oxide pathway might be beneficial in ameliorating ischemiareperfusion damage. However, research mainly focuses on nitric oxide supplementation of intracellular solutions, and no studies exist in which the effect of nitroglycerin on Perfadex preservation quality is evaluated.
\end{abstract}

Methods: Eight rat lungs each were preserved with Perfadex solution with or without nitroglycerin $(0.1 \mathrm{mg} / \mathrm{mL})$ and compared with low-potassium Euro-Collins solution. Postischemic lungs were reventilated and reperfused, and oxygenation capacity, pulmonary vascular resistance, and peak inspiratory pressures were monitored continuously. Stereological analysis was used for evaluation of pulmonary edema and assessment of the vasculature. Statistics were performed by using different analysis of variance models.

Results: The oxygenation capacity of the Perfadex-preserved groups was higher compared with that of the low-potassium Euro-Collins solution group $(P<.03)$. By using nitroglycerin, flush-perfusion time was reduced, and Perfadex solution with nitroglycerin-protected lungs showed superior oxygenation capacity compared with that seen in Perfadex solution-protected organs $(P<.01)$. Furthermore, pulmonary vascular resistance and peak inspiratory pressures were improved in the nitroglycerin group $(P<.01)$. Stereology revealed comparable intrapulmonary edema between groups and a trend toward less vasoconstricted vasculature in Perfadex with nitroglycerin-protected lungs.

Conclusions: Perfadex solution provides superior lung preservation in terms of postischemic oxygenation capacity than Euro-Collins solution. Supplementation of the nitric oxide pathway by nitroglycerin further enhances functional outcome of Perfadex-preserved organs and might be an easily applicable tool in clinical lung transplantation. 


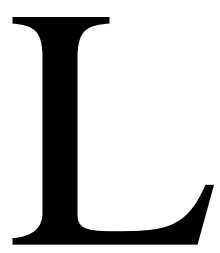

ung transplantation is actually considered an effective therapy in end-stage pulmonary disease, but its application is limited by the severe scarcity of suitable donor organs. Furthermore, the still-suboptimal preservation techniques lead to various degrees of ischemia-reperfusion injury. ${ }^{1}$ Therefore adequate preservation of the donor organ is an important issue to enhance the applicability of the procedure with the aim to reduce organ dysfunction, especially in the early postoperative period.

A number of different techniques for lung preservation have been proposed in the last decade, but most institutions still use single-flush perfusion with modified Euro-Collins solution (EC) administered through the pulmonary artery. ${ }^{2}$ Alternative products, such as the low-potassium dextran Perfadex solution (PER; Vitrolife AB, Göteborg, Sweden), have been developed recently to improve the quality of pulmonary allograft preservation. Those solutions of extracellular electrolyte composition have been shown to significantly reduce the ischemia-reperfusion injury, with excellent functional results in terms of postischemic oxygenation. ${ }^{3-5}$ Because it has been shown that maintaining vascular homeostasis in the pulmonary graft is one of the most important determinants for successful lung preservation and transplantation, ${ }^{6}$ numerous experiments have focused on the addition of different protective agents to the preservation solution. Endogenously produced nitric oxide (NO) is released from endothelial cells and represents one of the key factors for vascular homeostasis. As main effects, NO causes smooth muscle relaxation with regulation of pulmonary vascular tone, regulation of microvascular permeability, and inhibition of platelet aggregation. ${ }^{7}$ However, it has been shown that endogenous NO synthesis is significantly decreased during lung ischemia and reperfusion. ${ }^{8}$ Therefore investigators evaluated the effect of application of the NO donor nitroglycerin with subsequent stimulation of the cyclic guanosine monophosphate pathway and reported a significantly improved quality of lung preservation when administered during the early preservation period..$^{9-11}$ However, most of these reports still focused on lung preservation with EC, and there is little information thus far concerning the effect of NO donors as an adjunct to the modern extracellular-type preservation solutions. Therefore the goal of this study was to analyze the effect of nitroglycerin-enriched PER on the quality of lung preservation. In addition to the evaluation of postischemic lung function, lungs were further examined histologically by using standard stereological techniques that allow reliable and efficient quantification of intrapulmonary edema. ${ }^{12,13}$

\section{Material and Methods}

\section{Surgical Methods and Functional Assessment}

Lungs of 24 anesthetized and mechanically ventilated male inbred Sprague-Dawley rats (weight 450-500 g) were used for the exper-

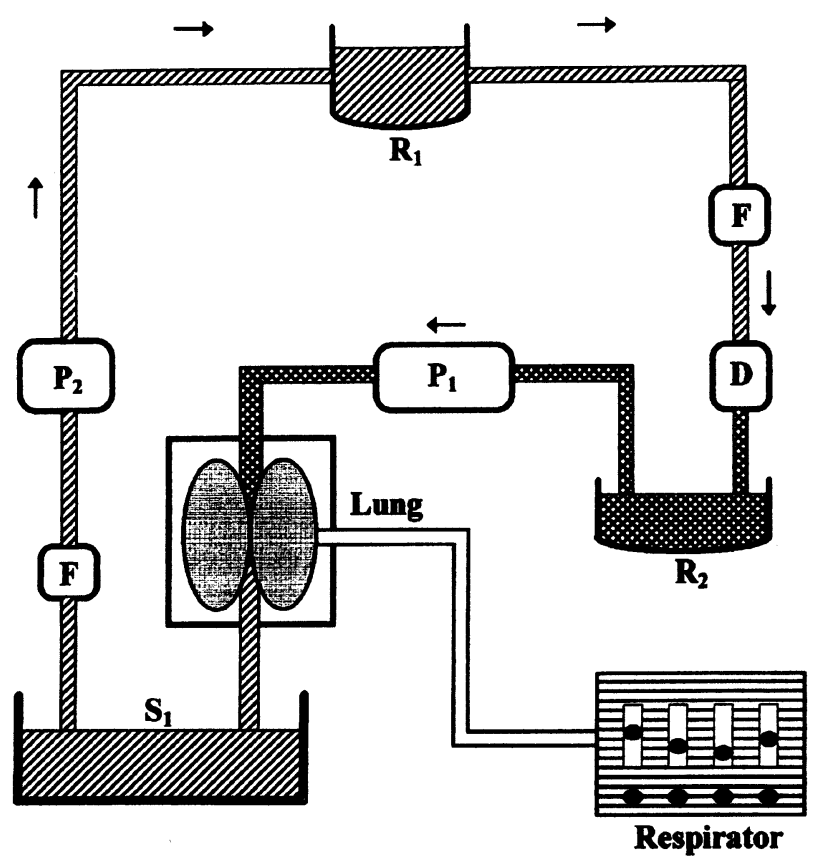

Figure 1. Extracorporeal lung circuit. The pulmonary artery is perfused with blood from the lower reservoir $\left(R_{2}\right)$ by a small roller pump $\left(\boldsymbol{P}_{1}\right)$ at a defined rate of $8 \mathrm{~mL} / \mathrm{min}$ with deoxygenated xenogenic perfusate. Lungs are ventilated with room air under physiologic time-pressure conditions provided by a small animal respirator. The pulmonary venous blood drains into the main reservoir $\left(S_{1}\right)$ and is recirculated by a second roller pump $\left(\boldsymbol{P}_{2}\right)$ into the upper reservoir $\left(R_{1}\right)$. Constant deoxygenation of perfusate is maintained with specifically gassed standard oxygenators (D). System temperature is controlled by use of water-jacketed vessels and a thermostat. Different filter systems are included (F).

iments. All animals received humane care in compliance with the "Principles of Laboratory Animal Care" formulated by the National Society for Medical Research and the "Guide for the Care and Use of Laboratory Animals" prepared by the Institute of Laboratory Animal Resources, National Research Council, and published by the National Academy Press, revised 1996. The experiments were performed by using an established extracorporeal rat lung model, as described in detail previously. ${ }^{14}$

After laparotomy and thoracotomy, rats were assigned to one of 2 experimental groups: 8 lungs each were preserved with either PER (Vitrolife Inc, Göteborg, Sweden) with (PER-NO) or without nitroglycerin (Glyceroltrinitrat, $0.1 \mathrm{mg} / \mathrm{mL}$; Schwarz Pharma, Monheim, Germany). All results were compared with those of the control lungs, which were preserved with modified low-potassium EC (LPEC; $40 \mathrm{mval} / \mathrm{L}$ potassium) with prostacyclin (Flolan, $6 \mu \mathrm{g}$ / $100 \mathrm{~mL}$; Glaxo Wellcome GmbH, Hamburg, Germany). Perfusion was performed by using $20 \mathrm{~mL}$ of the corresponding preservation solution at $4{ }^{\circ} \mathrm{C}$ and a constant pressure of $20 \mathrm{~cm} \mathrm{H}_{2} \mathrm{O}$ with recording of the flush perfusion time. Throughout the entire perfusion period, the lungs were ventilated to allow for a homogenous distribution of the perfusate. The heart-lung block was then care- 


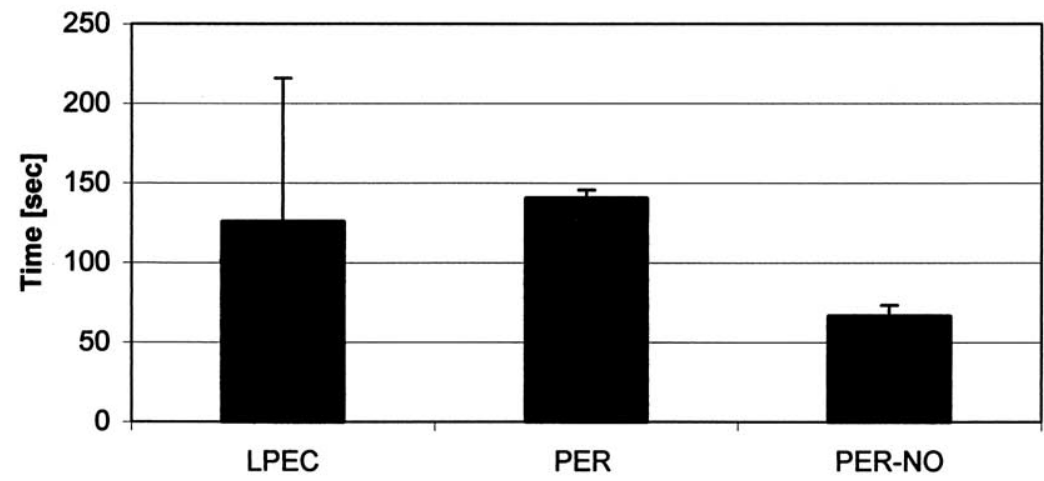

Figure 2. Flush perfusion time. Preservation groups were composed of LPEC, PER, and PER-NO: PER-NO versus PER, $P<.001$.

fully excised, and the lungs were inflated with $10 \mathrm{~cm}^{3}$ of room air and stored in the preservation solution at $10^{\circ} \mathrm{C}$.

After storage, the lungs were reventilated and reperfused with deoxygenated xenogenic perfusate containing bovine red blood cells through a pulmonary arterial cannula. This extracorporeal reperfusion circuit (Figure 1) consisted of a reservoir and a roller pump (Multiflow bloodpump; Stoeckert Instruments Ltd, Munich, Germany) to raise the perfusate to the reservoir. Also, a 40- $\mu \mathrm{m}$ blood filter (PALL Europe Ltd, Portsmouth, United Kingdom), a membrane oxygenator (Monolyth integrated membrane lung; Sorin Biomedica Ltd, Saluggia, Italy) that was gassed with $95 \%$ $\mathrm{N}_{2}$ and $5 \% \mathrm{CO}_{2}$, and a second roller pump (Reglo-Digital; Ismatec Inc, Zurich, Switzerland) for continuous lung perfusion were included. The perfusion rate was gradually increased from 1.0 to 8.0 $\mathrm{mL} / \mathrm{min}$ during the first 9 minutes and was maintained at a constant rate of $8.0 \mathrm{~mL} / \mathrm{min}$ throughout the remaining reperfusion period. All vessels were water-jacketed and temperature was controlled by using a warming pump (water thermostat type Lauda M3B; Omnilab, Germany) at $37^{\circ} \mathrm{C}$. Constant deoxygenation of the perfusate to a $\mathrm{Po}_{2}$ of 10 to $15 \mathrm{~mm} \mathrm{Hg}$ was achieved by means of regulation of gas flow. The opening of the left atrial cannula was positioned above the level of the atrium, ensuring a constant positive pressure of $2 \mathrm{~cm} \mathrm{H}_{2} \mathrm{O}$ (left atrial pressure).

Reperfusion time was limited to 50 minutes to specifically assess the early postischemic period. Pulmonary artery pressures and peak inspiratory pressures (PIPs) were measured continuously, and pulmonary vascular resistance (PVR) was calculated. Blood gases were determined in 10-minute intervals. For assessment of the oxygenation ability of the reperfused lungs, the oxygenation capacity was calculated $\left(\mathrm{PaO}_{2}-\mathrm{PvO}_{2}\right)$. At the end of each experiment, the entire left lung was excised, and the wet/dry (W/D) lung weight ratio was determined by using the fresh weight of the lung and the weight after storage for 48 hours in a cabinet dryer at $60^{\circ} \mathrm{C}$.

\section{Histologic Analysis}

In all groups after the period of ischemia and reperfusion, the entire right lung was processed for light microscopy after fixation by means of vascular perfusion through the pulmonary artery with a $1.5 \%$ paraformaldehyde-glutaraldehyde solution in $0.1 \mathrm{~mol} / \mathrm{L}$
$\mathrm{N}$-2-hydroxyethylpiperazine-N-2-ethanesulfonic acid buffer at a pressure of $15 \mathrm{~cm} \mathrm{H}_{2} \mathrm{O}$. During fixation, the lungs were inflated, with a constant pressure of $12 \mathrm{~cm} \mathrm{H}_{2} \mathrm{O}$. The tissue was dehydrated through a graded series of ethanol and embedded in a methacrylate resin (Technovit 7100; Kulzer, Heraeus, Germany). Systematic random sampling of tissue was performed according to the method of Michel and Cruz-Orive ${ }^{15}$ to collect lung material representative of the whole lung. Slices of $3 \mathrm{~mm}$ in thickness were cut from each lung (9-12 per lung) and stained with methyleneblue/Azur II (1:2). All parameters were determined at the light microscopic level by using established stereological techniques, ${ }^{12,13}$ with a Leitz Laborlux 11 and a Zeiss Axioskop equipped with a projection tube.

Statistical evaluation of W/D weight ratio, relative volume of total lung edema, and vessel diameters was performed by using analysis of variance with multiple comparisons. Oxygenation and hemodynamic parameters during the reperfusion period were analyzed by using analysis of variance with repeated measurements.

\section{Results}

\section{Flush Perfusion Time}

The perfusion time (Figure 2) was significantly lower in the PER-NO group compared with that in the PER group (PERNO, $67 \pm 7$ seconds; PER, $141 \pm 5$ seconds, $P<.001)$. Perfusion time was longest but extremely variable in the LPEC group (126 \pm 90 seconds), and this difference did not reach statistical significance when compared with PERNO- or PER-protected lungs.

\section{Oxygenation Capacity}

After the ischemic period, all reperfused lungs resumed sufficient function. Use of PER was associated with a trend toward better oxygenation capacity (Figure 3), but the difference did not reach statistical significance because of the high variability in the PER group $(P=.079)$. However, the oxygenation capacity of the PER-NO group was found to be significantly higher compared with that of both LPEC lungs $(P<.001)$ and PER-protected organs $(P=.001)$. 


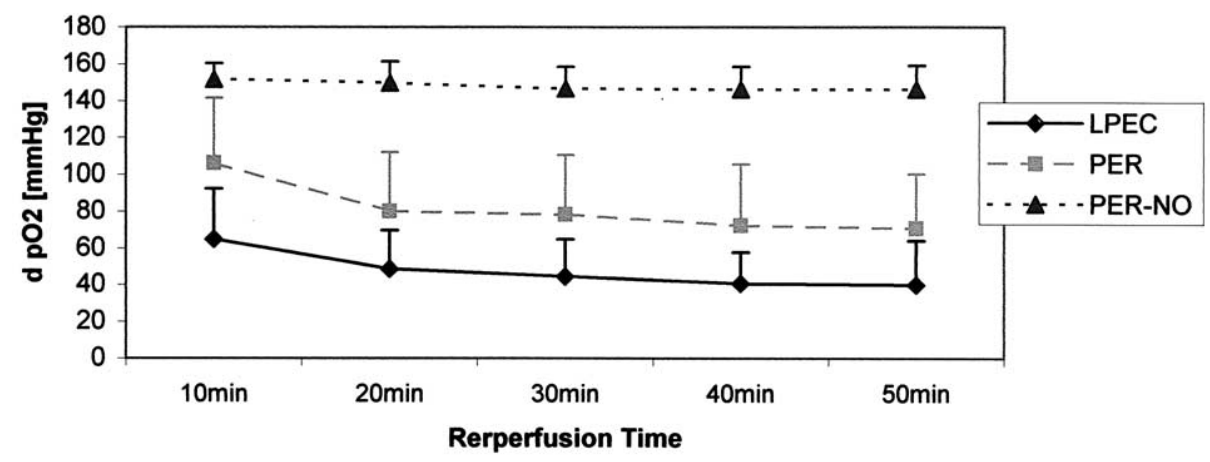

Figure 3. Oxygenation capacity $\left(\mathrm{PaO}_{2}-\mathrm{Pvo}_{2}\right)$ of rat lungs during the observation period of 50 minutes. Preservation groups were composed of LPEC, PER, and PER-NO: PER-NO versus PER, $P=.001$; PER-NO versus LPEC, $P<.001$.

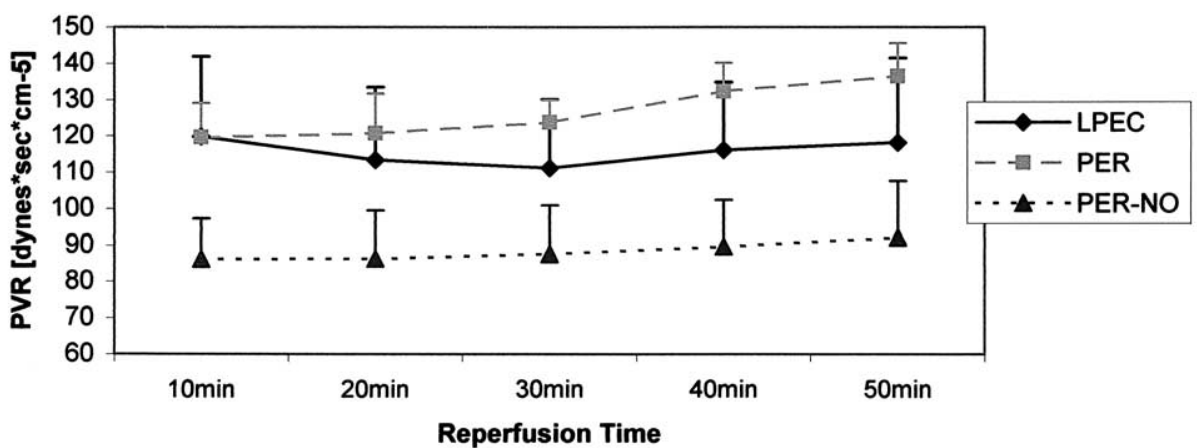

Figure 4. PVR of rat lungs during the observation period of 50 minutes. Preservation groups were composed of LPEC, PER, and PER-NO: PER-NO versus PER, $P<.001$; PER-NO versus LPEC, $P=.001$.

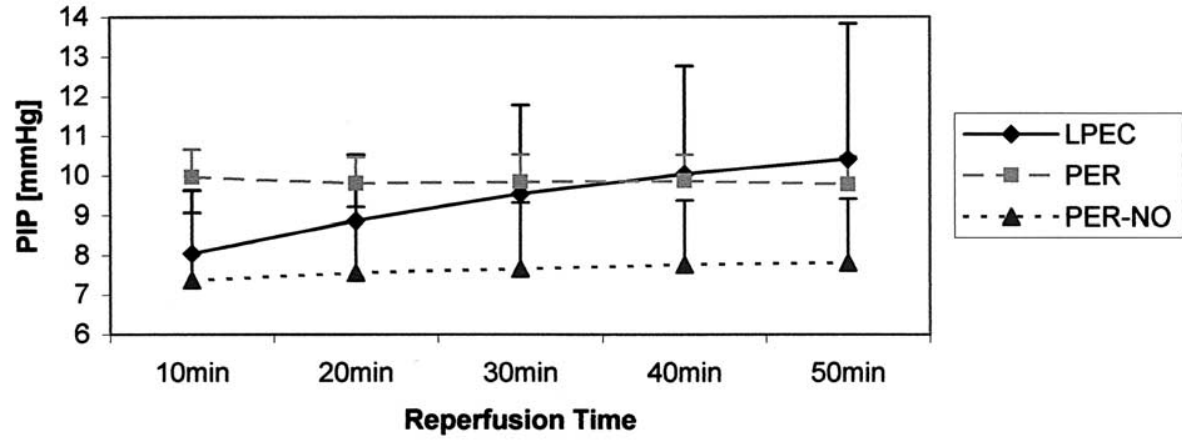

Figure 5. PIP of rat lungs during the observation period of 50 minutes. Preservation groups were composed of LPEC, PER, and PER-NO: PER-NO versus PER, $P=.018$.

Pulmonary Vascular Resistance

In all study groups, PVR increased toward the end of the reperfusion period (Figure 4). Although use of PER was associated with similar PVR values when compared with LPEC, lung preservation with PER-NO resulted in a significant reduction of PVR in comparison with values in both the $\operatorname{LPEC}(P=.001)$ and PER $(P<.001)$ groups.
Peak Inspiratory Pressure

After PER and PER-NO preservation, PIP was found to be nearly unchanged over the reperfusion period (Figure 5). In contrast, PIP values increased toward the end of the reperfusion period after LPEC preservation. Although use of PER was associated with similar PIP values when compared with user of LPEC, lung preservation with PER-NO re- 


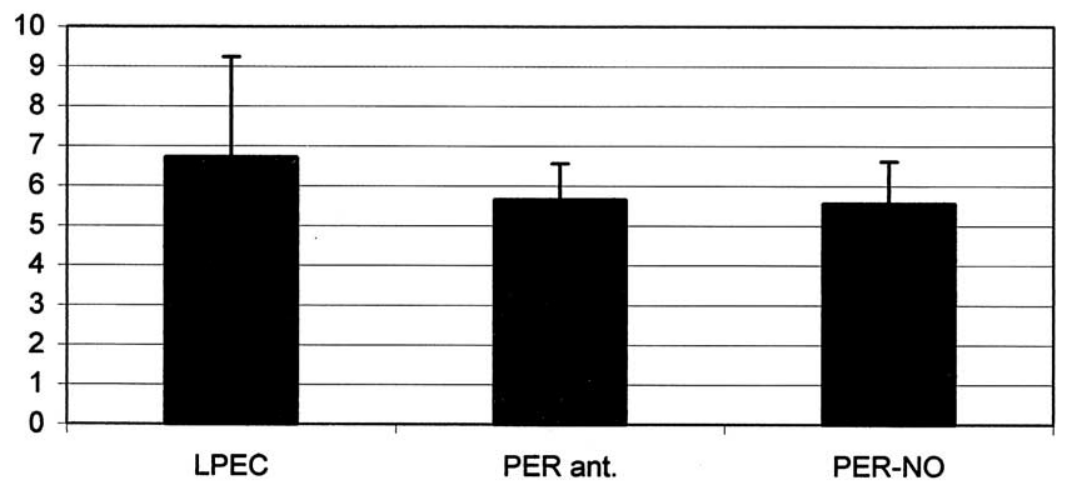

Figure 6. W/D weight ratio of rat lungs after the observation period of 50 minutes. Preservation groups were composed of LPEC, PER, and PER-NO. Differences were statistically not significant.

sulted in a significant reduction of PIPs compared with values the PER group $(P=.018)$.

\section{W/D Ratio}

Although there was a trend toward lower W/D ratios in PER-protected (5.65 \pm 0.91$)$ and PER-NO-protected (5.56 $\pm 1.06)$ organs compared with those seen in LPEC-protected organs $(6.72 \pm 2.52)$, the noticed differences were not significant (Figure 6).

\section{Stereology}

The relative volume fraction of edema (Figure 7) referred to total lung volume was highest in LPEC-protected lungs $(16.85 \% \pm 10.1 \%$; Figure $8, B)$, whereas a significantly lower amount of edema was observed after both PER $(1.22 \% \pm 1.1 \%)$ and PER-NO $(3.11 \% \pm 3.27 \%)$ preservation $(P=.003$; Figure $8, A)$. The differences between both PER-preserved groups were not statistically significant. Stereological examination of relative volume fractions of vessel lumen, vessel wall, and the calculated lumen/wall ratio revealed results that did not reach statistical significance. However, in contrast to the LPEC and PER groups, the lumen/wall ratio of PER-NO-protected organs was found to be almost identical to that seen in untreated control lungs (Figure 9).

\section{Discussion}

Lung transplantation is considered to be an effective treatment for many types of end-stage pulmonary disease. Compared with initial results, the improved outcome is mainly related to optimized immunosuppression regimens and modified protocols for pulmonary preservation. However, early graft dysfunction is still a continuing problem, resulting from a multifactorial lung injury starting within the donor and continuing during harvesting, organ storage, implantation, and postischemic reperfusion. Modified EC is currently most widely used for lung preservation. ${ }^{2}$ How- ever, it is well known that the high potassium concentration of EC can cause severe pulmonary vasoconstriction, followed by edema formation. ${ }^{16}$ This vasocontrictive effect can lead to inhomogeneous perfusion caused by potassiuminduced vasospasm with a resulting prolongation of flush preservation times. ${ }^{16}$ Accordingly, preservation time in our series was longest when EC was used for lung preservation. However, the high variability of flush preservation time in our EC group is not well explained and has to be further elucidated in future experiments.

Most centers still apply prostacyclin as an adjunct to the EC to protect the lungs from inhomogeneous perfusion caused by potassium-induced vasospasm. ${ }^{17}$ In recent years, extracellular-type low-potassium solutions, such as PER, have been developed for improvement of pulmonary preservation by minimizing vasospasm, consequently leading to a more homogeneous distribution of the flush solution with superior functional results. ${ }^{3-5}$ Because of the low potassium content of PER, the need for additional application of prostaglandins has been resolved. Furthermore, there has been a reasonable amount of evidence in the past that prostaglandins are either of no use ${ }^{18,19}$ or even harmful. ${ }^{20}$ However, a number of different techniques for improvement of lung preservation have been proposed recently as a result of the fact that the pulmonary vasculature seems to play a significant role in ischemia and reperfusion-induced lung injury. ${ }^{6}$ Among the numerous factors maintaining pulmonary vascular homeostasis, NO is released from endothelial cells and serves as an endothelium-derived relaxing factor that elicits vasorelaxation mainly through activation of guanylate cyclase with a subsequent increase of cyclic guanosine monophosphate levels. ${ }^{21} \mathrm{NO}$ serves as an important signaling molecule to reduce vasomotor tone of vascular smooth muscles, ${ }^{11}$ to maintain endothelial barrier function, ${ }^{22}$ to reduce platelet aggregation, ${ }^{23}$ and to inhibit neutrophil adherence to the endothelial surface. ${ }^{24}$ After pulmonary isch- 


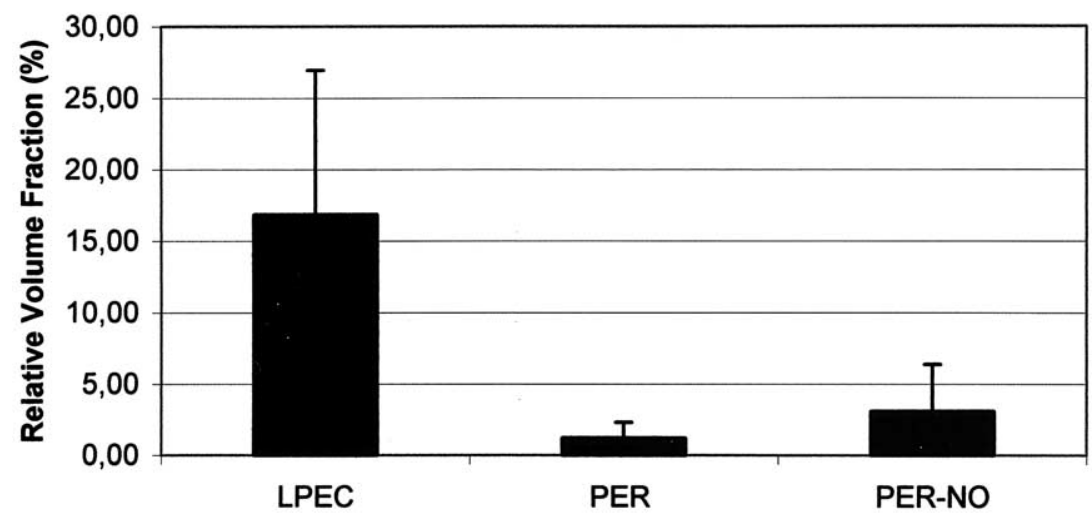

Figure 7. Volume fraction of intra-alveolar edema in rat lungs after the observation period of 50 minutes. Preservation groups were composed of LPEC, PER, and PER-NO. Differences were statistically not significant.
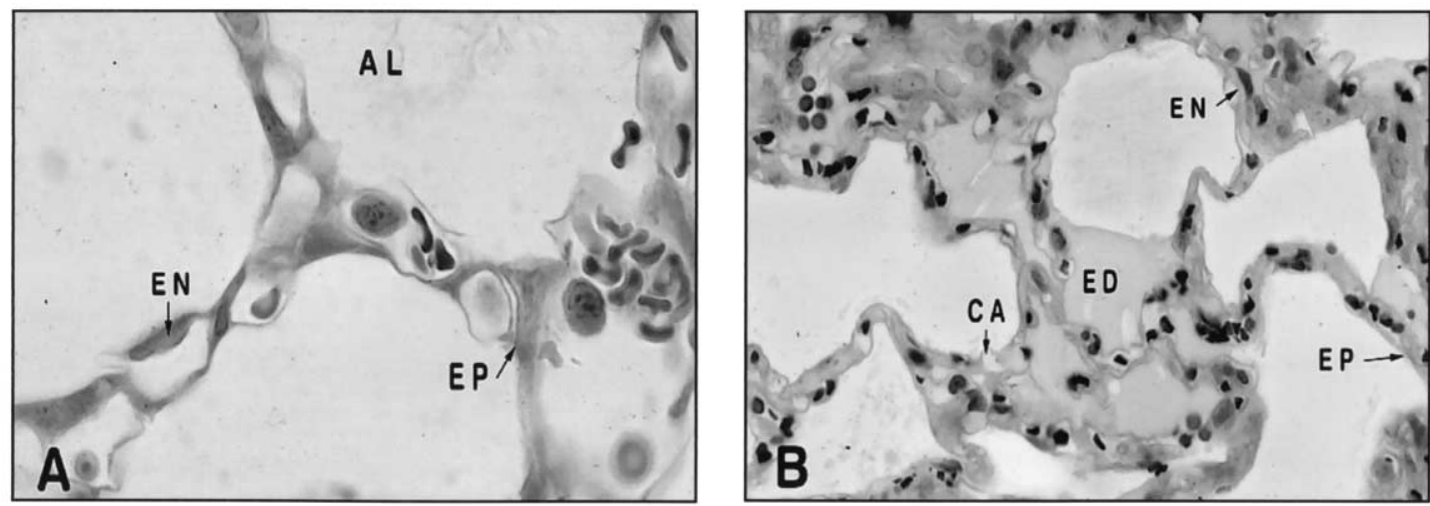

Figure 8. Sections of lung parenchyma after preservation with PER ( $A$; normal histologic structure without edema) and modified EC ( $B$; formation of intra-alveolar edema). $A L$, Alveolus; $E N$, endothelial cell; $E P$, epithelial cell; $C A$, capillary; ED, edema.

emia in the setting of lung transplantation, these physiologic endothelial properties are perturbed, which predisposes to vasoconstriction, neutrophil adhesion, and thrombosis as the ischemia-reperfusion response is activated. Systemic endogenous NO levels are found to be significantly diminished after endothelial exposure to ischemia and reperfusion, which is considered to be due to immediate inactivation by the rapidly produced highly toxic superoxide anion during early reperfusion. ${ }^{25}$ As a circulus vitiosus, the lack of available NO is considered to contribute to endothelial dysfunction and pulmonary graft failure during reperfusion. Therefore several groups investigated the effect of the NO donor nitroglycerin as an adjunct to the preservation solution and reported significantly improved quality of lung preservation. ${ }^{8,9,11}$ However, most of these reports still focused on lung preservation with EC, and no studies exist concerning the effect of nitroglycerin on PER-based lung preservation.
Our experiments were thought to evaluate whether this promising treatment is also suitable to further enhance the published excellent preservation properties of the low-potassium-dextran PER. Because the isolated rat lung seems to be an ideal screening model for assessment of early postpreservation lung function, we used our established xenogenic, perfused small-animal model, as described previously. ${ }^{14}$ Obviously autologous blood would have been the optimal perfusate for the experiments. However, in this rat model only $6 \mathrm{~mL} / 100 \mathrm{~g}$ of whole blood can be withdrawn from a single rat. Therefore the amount of animals that would have to be killed for one experiment contradicts the advantage of a low-cost screening model. For this reason, we used bovine red blood cells, as described by Lieberthal and associates, ${ }^{26}$ which do not restrict the experiments to the use of rodent red blood cells. ${ }^{27}$

In the past, there has been evidence that even after short ischemic periods of 2 to 4 hours, primary ultrastructural 


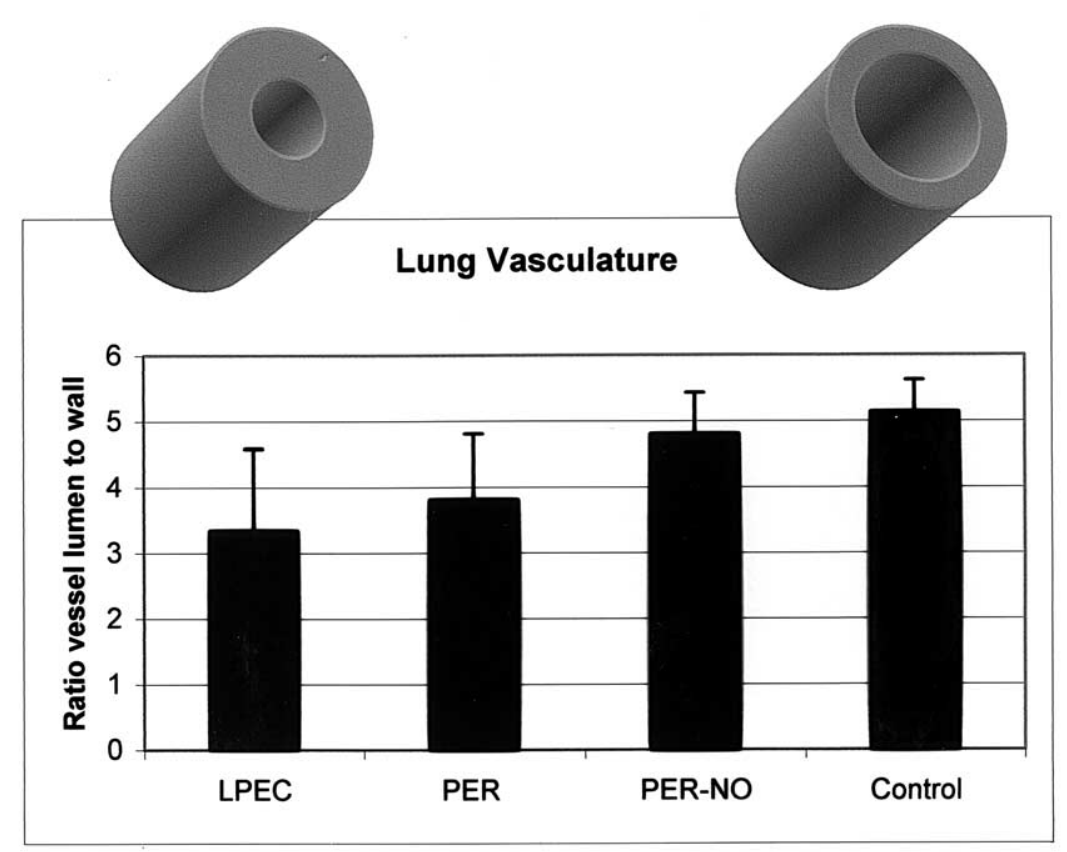

Figure 9. Ratio of stereologically determined volume fractions of vessel lumen to vessel wall. Preservation groups were composed of LPEC, PER, and PER-NO. Differences were statistically not significant. Control, Untreated normal control lungs.

damage to the pulmonary surfactant system might occur. A significantly increased permeability of the pulmonary endothelium is considered to have important implications on the initiation and extent of acute postischemic reperfusion edema. ${ }^{28}$ Therefore we decided to perform all experiments at this rather short ischemic period of 4 hours to facilitate future analyses of intrapulmonary surfactant and its degradation products in early ischemia. Because it was reported recently that the potential posttransplantation benefits of exogenous nitroglycerin application are restricted to lungs that were supplemented during the early harvest and immersion period, ${ }^{10}$ the nitroglycerin in our series was added to the preservation solution only. The dose of $0.1 \mathrm{mg} / \mathrm{mL}$, which was used for the experiments, is recommended in the literature. ${ }^{8,9}$

In these experiments reperfusion time was limited to 50 minutes, which is considered to be sufficient to specifically assess the early postischemic period. ${ }^{27}$ Obviously a longer reperfusion period would deliver additional important information because reperfusion injury clearly occurs over a longer time period. Therefore the conclusions of this study are limited by the rather short observation period used in the experiments.

During reperfusion, the lowest oxygenation capacity was found in LPEC-protected lungs, whereas the oxygenation capacity of PER-NO-preserved organs was significantly higher compared with that of both LPEC- and PER-protected organs $(P<.03)$. However, a rather high variability of oxygenation capacity was found in the PER group that is not well explained and has to be further evaluated in additional experiments. Overall, the results obtained with nitroglycerin in PER confirm the available reports on the basis of lung preservation with high-potassium solutions. ${ }^{8,11,29}$ Additionally, the PVR was found to be significantly reduced when PER-NO was used for preservation in contrast to LPEC and PER, which was similarly reported by others. ${ }^{10,29,30}$ Interestingly, the histologic analysis revealed a trend toward a less constricted pulmonary vasculature, which was expressed by a stereologically evaluated similar high ratio of vessel lumen to vessel wall as that seen in untreated normal control lungs. This finding might represent the histologic correlate for the functional finding of lower PVR in the PER-NO group. In contrast, the LPEC and PER groups showed lower values, indicating a reduced relative vessel lumen. However, the beneficial effects of nitroglycerin supplementation are considered to be not exclusively the result of its action as a vasodilator, because other potent vasodilators, such as hydralazine, were found to be of no comparable effect in terms of postischemic lung function. ${ }^{11}$

Recently, it was shown that endothelin 1 (ET-1) plays a pivotal role in the control of pulmonary vascular tone. ${ }^{31,32}$ ET-1 is one of the most potent vasocontrictors known and is synthesized and released by multiple cell types, especially by vascular smooth muscle cells and endothelial cells. ${ }^{33}$ Accumulating evidence exists that endogenous NO inhibits ET-1 production at the transcriptional level, ${ }^{34}$ and their 
reciprocal balance largely determines the regulation of vascular tone. ${ }^{35}$ Recent investigations found a striking increase in the expression of ET- 1 mRNA and ET-1 peptide after lung transplantation and reperfusion. This process is considered to result in an increase of recipient PVR and increased vascular permeability. In contrast, ET-1 mRNA was significantly suppressed by the presence of exogenous nitroglycerin at the onset of preservation, even during extended periods of cold pulmonary preservation ${ }^{10}$ Interestingly, in the same investigation the postischemic PVR was found to be unchanged when nitroglycerin was administered at the end of the flush preservation or during ex vivo flushing. As an explanation, it appears that loss of endogenous NO in the graft during preservation leads to upregulation of ET-1 expression in the pulmonary vasculature and subsequent irreversible vasoconstriction, which can not be altered, even with the administration of exogenous nitroglycerin immediately before reperfusion. On the basis of their positive findings after EC preservation, the authors concluded that exogenous nitroglycerin given early during the preservation period enhances posttransplantation pulmonary function at least in part by modulation of ET-1 synthesis. Although we did not perform measurements of ET-1 expression in our series, the observed results indicate that supplementation of the PER with nitroglycerin can significantly improve the postischemic functional results in terms of oxygenation and PVR after moderate pulmonary ischemia. In contrast, lung preservation with modified EC is associated with inferior oxygenation and hemodynamics in combination with a significantly higher amount of intraalveolar edema. Because the relative volume fraction of intra-alveolar edema was found to be comparable after preservation with PER with and without the addition of nitroglycerin, we hypothesize that the underlying mechanism of action might at least in part be a significantly suppressed induction of ET-1 in the graft during preservation and cold storage.

Additional experiments with this extracorporeal rat lung model with extended ischemic and postischemic observation periods and an additional in vivo porcine model with evaluation of ET-1 kinetics are being initiated to further elucidate the promising results of nitroglycerin-supplemented PER. This approach could represent an easily applicable tool in clinical lung transplantation and has the potential to further improve the excellent results of lung preservation with PER, which has gained increased worldwide acceptance in recent years. ${ }^{36,37}$

We gratefully acknowledge the expert technical assistance of S. Kirste, A. Apel, S. Freese, A. Gerken, H. Hühn, and M. Kirste.

\section{References}

1. Haverich A. Experience with lung transplantation. Ann Thorac Surg. 1999;76:305-12.
2. Hopkinson DN, Bhabra MS, Hooper TL. Pulmonary graft preservation: a worldwide survey of current clinical practice. J Heart Lung Transplant. 1998; 17:525-31.

3. Sakamaki F, Hoffmann H, Mueller C, Dienemann H, Messmer K, Schildberg FW. Reduced lipid peroxydation and ischemia-reperfusion injury after lung transplantation using low-potassium dextran solution for lung preservation. Am J Respir Crit Care Med. 1997;156:1073-81.

4. Müller C, Fürst H, Reichenspurner H, Briegel J, Groh J, Reichart B. Lung procurement by low-potassium dextran and the effect on preservation injury. Transplantation. 1999;68:1139-43.

5. Fischer S, Matte-Martyn A, dePerrot M, et al. Low-potassium dextran preservation solution improves lung function after human lung transplantation. J Thorac Cardiovasc Surg. 2001;120:594-6.

6. Ingemansson R, Sjöberg T, Steen S. Importance of calcium in longterm preservation of the vasculature. Ann Thorac Surg. 1996;61:115862.

7. Lefer AM, Lefer DJ. Pharmacology of the endothelium in ischemiareperfusion and circulatory shock. Annu Rev Pharmacol Toxicol. 1993; 33:71-90.

8. Pinsky DJ, Naka Y, Chowdhury NC, et al. The nitric oxide/cyclic GMP pathway in organ transplantation: critical role in successful lung preservation. Proc Natl Acad Sci U S A. 1994;91:12086-90.

9. Naka Y, Chowdhury NC, Oz MC, et al. Nitroglycerin maintains graft vascular homeostasis and enhances preservation in an orthotopic rat lung transplant model. J Thorac Cardiovasc Surg. 1995;109:206-11.

10. Minamoto K, Pinsky DJ, Fujita T, Naka Y. Timing of nitric oxide donor supplementation determines endothelin-1 regulation and quality of lung preservation for transplantation. Am J Respir Cell Mol Biol. 2002;26:14-21.

11. Naka Y, Chowdhury $\mathrm{NC}$, Liao $\mathrm{H}$, et al. Enhanced preservation of orthotopically transplanted rat lungs by nitroglycerin but not hydralazine. Circ Res. 1995;76:900-6.

12. Fehrenbach H, Ochs M. Studying lung ultrastructure. In: Uhlig S, Taylor AE, editors. Methods in pulmonary research. Basel: Birkhaeuser, 1998. p. 429-54.

13. Fehrenbach A, Fehrenbach H, Wittwer Th, Ochs M, Wahlers Th, Richter J. Evaluation of pulmonary edema: stereological versus gravimetrical analysis. Eur Surg Res. 2001;33:270-8.

14. Wittwer T, Wahlers T, Fehrenbach A, et al. Combined use of prostacyclin and higher perfusate temperatures further enhances the superior lung preservation by Celsior solution in the isolated rat lung. J Heart Lung Transplant. 1999;18:684-92.

15. Michel RP, Cruz-Orive LM. Application of the Cavalieri principle and vertical sections method to the lung: estimation of volume and pleural surface area. J Microsc. 1988;150:117-36.

16. Kimblad PA, Sjöberg T, Massa G, Solem JO, Steen S. High potassium contents in organ preservation solutions causes strong pulmonary vasoconstriction. Ann Thorac Surg. 1991;52:523-8.

17. Mulvin D, Jones K, Howard R, Grosso M, Repine J, Johnston M. The effect of prostacyclin as a constituent of a preservation solution in protecting lungs from ischemic injury because of its vasodilator properties. Transplantation. 1990;49:828-30.

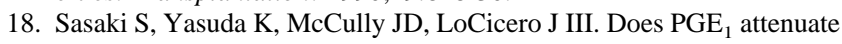
potassium-induced vasoconstriction in initial pulmonary artery flush on lung preservation? J Heart Lung Transplant. 1999;18:139-42.

19. Ueno T, Yokomise H, Oka T, et al. The effect of PGE1 and temperature on lung function following preservation. Transplantation. 1991; 52:626-30.

20. Kukkonen S, Heikkilä LJ, Verkkala K, Mattila SP, Toivonen H. Prostaglandin $\mathrm{E}_{1}$ or prostacyclin in Euro-Collins solution fails to improve lung preservation. Ann Thorac Surg. 1995;60:1617-22.

21. Moncada S, Palmer RM, Higgs FA. Nitric oxide: physiology, pathophysiology, and pharmacology. Pharmacol Rev. 1991;43:109-42.

22. Fantone JC, Funkel SL, Ward PA, Zurier RB. Suppression by prostaglandin E1 of vascular permeability induced by vasoactive inflammatory mediators. J Immunol. 1980;125:2591-6.

23. Moncada S, Flower RI, Vane JR. Prostaglandins, prostacyclin, thromboxane A2 and leukotriens. In: Gilman AG, Goodman LS, Rall TW, Murad F, editors. The pharmacologic basis of therapeutics. New York: Macmillan; 1985. p. 660-73. 
24. Jones G, Hurley JV. The effect of prostacyclin in the adhesion of leucocytes to injured vascular endothelium. J Pathol. 1984;142:51-9.

25. Pinsky DJ, Oz MC, Koga S, et al. Cardiac preservation is enhanced in a heterotopic rat transplant model by supplementing the nitric oxide pathway. J Clin Invest. 1994;93:2291-7.

26. Lieberthal W, Vasilevski ML, Valeri CR, Levinsky NG. Interactions between $\mathrm{ADH}$ and prostaglandins in isolated erythrocyte-perfused rat kidneys. Am J Physiol. 1987;252:F331-7.

27. Fukuse T, Albes JM, Takahashi Y, Brandes H, Hausen B, Schaefers HJ. Influence of red blood cells on lung function in an ex vivo rat heart-lung model. J Surg Res. 1995;59:399-404.

28. Fehrenbach A, Ochs M, Wahlers T, et al. Beneficial effect of lung preservation is related to ultrastructural integrity of tubular myelin after experimental ischemia and reperfusion. Am J Respir Crit Care Med. 2000;161:2058-65.

29. Bhabra MS, Hopkinson DN, Shaw TE, Hooper TL. Relative importance of prostacyclin/cyclic adenosine monophosphate and nitric oxide/cyclic guanosine monophosphate pathways in lung preservation. Ann Thorac Surg. 1996;62:1494-9.

30. Bando T, Albes JM, Schöne J, et al. Significance of cyclic adenosine monophosphate and nitroglycerin in ET-Kyoto solution for lung preservation. Ann Thorac Surg. 2000;69:887-92.

31. Mizutani H, Minamoto K, Aoe M, et al. Expression of endothelin-1 and effects of an endothelin receptor antagonist, TAK-044, at reperfusion after cold preservation in a canine lung transplantation model. J Heart Lung Transplant. 1998;17:835-45.

32. Miyauchi T, Masaki T. Pathophysiology of endothelin in the cardiovascular system. Annu Rev Physiol. 1999;61:391-415.

33. Simonson MS, Dunn MJ. Endothelin: pathways of transmembrane signaling. Hypertension. 1990;15:5-12.

34. Kourembas S, McQuillan LP, Leung GK, Faller DV. Nitric oxide regulates the expression of vasoconstrictors and growth factors by vascular endothelium under both normoxia and hypoxia. J Clin Invest. 1993;92:99-104.

35. Terzl F, Henrion D, Colucci-Guyon E, et al. Reduction of renal mass is lethal in mice lacking vimentin: role of endothelin-nitric oxide imbalance. J Clin Invest. 1997;100:1520-8.

36. Müller C, Bittmann I, Hatz R, et al. Improvement of lung preservation-from experiment to clinical practice. Eur Surg Res. 2002;34:7782 .

37. Strüber M, Wilhelmi M, Harringer W, et al. Flush perfusion with low-potassium dextran solution improves early graft function in clinical lung transplantation. Eur J Cardiothorac Surg. 2001;19:190-4.

\section{Discussion}

Dr Vaughn A. Starnes (Los Angeles, Calif). We know that Euro-Collins solution can tend to be vasoconstrictive, and that is the reason we started using prostacyclin way back when. Do you have a group there in which you compared prostacyclin/EuroCollins with PER?

Dr Albes. Yes. In this particular model we added prostacyclin to our Euro-Collins solution and compared it with both PER groups.

Dr Thomas K. Waddell (Toronto, Ontario, Canada). I congratulate you on your study. I think I generally believe the results, but I would like to comment about some other potential control groups that you might have included. Obviously nitroglycerin is a vasodilator, and therefore you might consider, and I think you suggested it yourself, that the flush time is shorter and, in fact, the flush efficiency might be greater in the presence of a vasodilator. Not to say that nitroglycerin is bad, but it might not be working entirely through the NO pathway. Also, NO has other effects that are mediated not through cyclic guanosine monophosphate (cGMP). Therefore, you could try other ways of targeting both the cGMP pathway and the non-cGMP pathway downstream of NO to determine what exactly is responsible for the mechanism of benefit.

Dr Albes. Thank you for this comment. It is certainly clear that we can investigate much more. We intend to perform a largeanimal study to verify these initial findings, especially regarding NO's effects on the microvasculature.

Dr Irving L. Kron (Charlottesville, Va). I have one question. NO has two faces, as you well know. Let us assume that it has the effects you think it does. If you give it to a lung that is not having any difficulty, it would work perfectly. But let us say injury has already occurred, and many of us believe reperfusion injury is part of the neurogenic pulmonary edema and that we just caught it at the wrong time. Could it potentially have a deleterious effect in that situation?

Dr Albes. NO surely has two faces because it is still a free radical. Deleterious effects might therefore occur. However, those were not observed by us. Unfortunately, it has always been a problem in a small-animal experimental study to investigate many details. We therefore had to remain concise and focus on just a few aspects in our laboratory work. 